\title{
Y Factory Study on Lean Production Management
}

\author{
Yung-Chih Chen \\ Feng Chia University \\ E-mail addressycchen5756@yahoo.com.tw
}

\begin{abstract}
Taiwan's small to the medium-sized traditional manufacturing industry is generally believed to have flourished in the 1970s due to the encouragement of the government to promote turning family living rooms into factories. With the hardworking attitude, these small factories were able to accumulate tiny good results and to converge into a significant force. Gradually, these family factories began to grow stronger, and they tried desperately to increase their productivity. They began to follow the model of standardization and mass production. However, did everything possible to reduce costs and to improve international competitiveness? In the study, we used $Y$ Factory as an example to figure out their difficulties and achievements.
\end{abstract}

Keywords: TPS, Lean Production, Lean Management.

\section{INTRODUCTION}

This is an open access article under the CC-BY-NC license.

Plenty of factories began to experience inventory pressure and encountered the pressure of switching production lines. All these were because they tried to meet the needs of customers. Everyone believed that as long as there are enough production capacity and sufficient inventory, they can satisfy customer's needs as much as possible. In this way, there will be sufficient orders to meet the production demand of the factory.

The manufacturing industry in Japan also encountered an identical problem during the same period of time. The Japanese automaker, Toyota Moto, first proposed a set of reform plans. They have realized that the automobile industry in the future will no longer be producing in a single specification mode. Instead, the production model will mainly focus on low-volume/diversifiedproducts with different forms and different styles. For the survival of the auto factory, they must carry out the reform.

As early as the 1980s, a team headed by Mr. Taiichi Ohno of Toyota Moto of Japan proposed Toyota Production mode. The Toyota Production System is based on a very simple principle which is mainly focusing on customer needs and requirements and improving all kinds of waste; increasing the overall yield; reducing inventory level; shortening the production cycle. It also required all employees to achieve just in time production and comprehensive quality inspection.

This production method has aroused tremendous reverberation in the Japanese manufacturing industry. We call this Toyota style production system TPS (TOYOTA Production System). The core value of the production method lies in just-in-time production/comprehensive quality inspection and automation. 
However, this production system has certain requirements to meet. It must be in a stable state. In addition, the quality and professionalism of the personnel must reach a certain level. This is to say, the obedience and execution ability of the employee must reach a certain professional level so that the execution of the system will not fall into chaos.

In light of this, some world-class manufacturers also want to implement this production system. However, the obedience and execution ability of the employee cannot reach a certain level.

\section{LITERATURE REVIEW}

In the year 1985, there was a research project, International Motor Vehicle Program, At MIT (Massachusetts Institute of Technology). The project was executed by three experts: James P. Womack, Daniel T. Jones, and Daniel Roos.

These three scholars studied the Toyota Production System (TPS). They thought TPS contains Japanese culture and spirit, thus not suitable for the whole world. So, they extracted the quintessential part of TPS and made some improvements. They published the book entitled "The Machine that Change the world" in 1990. It extended the TPS concept into Lean Production and promoted the concept to the whole world.

In respect of the introduction of TPS to Taiwan, because the main characters of the system, such as Taiichi Ohno and Shigeo Shingo and other advanced seniors, they all have a certain relationship with Taiwan's manufacturing industry. Coupled with the historical relationship between Taiwan and Japan, Taiwan has a certain leading edge over other advanced countries in the implementation of TPS.

Due to the influence of world trends currently, Taiwan's traditional manufacturing industry has begun to focus on the "Lean Management" based production method. It was traced back to on so-called "Lean System Revolution," translated by Zhong Hanging and published by Dieming Academy in 1997.

Fine: means that the spirit is to pursue "comprehensive quality control," end at perfection.

Real: refers to that it is to eliminate all kinds of waste in order to create real value and Wealth.

System: refers to that it is fundamentally pursuing the whole, upstream and downstream, value stream, and assist in production.

R\&D: commercial transaction processing; on service, it can create the product's co-prosperity and profitable overall action.

Revolution: there is a huge difference between the overall optimization idea and the current system. To implement this concept, conceptually, we need to give up many old ideas, attitudes, and practices.

\section{RESEARCH METHODOLOGY}

\section{OKR (Objective and Key Results)}

This is a goal-setting principle that is applicable to the company, team, and individual. (John Doerr, 2018) However, it cannot make a clear judgment and provide strong leadership or make ingenious new ideas for us. This is a new set of management methods that helps to ensure the company stays focused and be able to concentrate on dealing with the most important issues in the whole organization. 
If the goal is set and used properly, it can prevent the employee from having vague concepts and the slacking off mentality while performing operations. However, the setting of goals may also cause systemic problems in the organization because the setting of goals will blur the focus. In order to achieve the goals, employees may have unethical deviations in behavior and increase the possibility of risk-taking. It may also increase the damage rate of the cooperation between colleagues and reduce the enthusiasm of employees. So, it must be very careful when setting goals.

For example, In order to win the trust of customers, European car manufacturers did not hesitate to produce fake data to deceive consumers. As another example, Japanese steel plants do not hesitate to produce fake data to win the trust of customers in order to make their sales performance better. These are all inappropriate behaviors.

In 1968, Edwin Locke, a professor of psychology at the University of Maryland, proposed that difficult goals are more effective in improving performance than easy goals. Clear and difficult goals can bring up a higher level of output than vague and difficult goals. (John Doerr, 2018) In the following decades, many experiments have confirmed that the theory is correct. Clear and challenging goals can boost productivity. Regarding how to make employees dedicated and happy, there was a research finding that clearly defined and documented open goals can make the teamwork tightly together and let employees satisfied with their jobs. If there are problems with goal setting, such as the priority is in conflict or the goal is altered at will, employees will be frustrated and lose motivation.

Main features of the OKR system :

1. Focus on prioritized tasks

2. Align and connect for teamwork

3. Track for accountability

4. Stimulate potential, achieve breakthrough

In order to understand how companies are studying Lean management, this research adopts case analysis in order to understand what kind of difficulties might be encountered during the process of executing Lean Production and how to resolve the problems. It will also use data collection and information processing to analyze and summarize the execution results of Lean Production. Through the case analysis and rely on LP to improve the process and reduce unnecessary wastes, thereby boost the manufacturing capacity and lower the cost.

\section{FINDING AND DISCUSSION}

At the current stage of Taiwan's traditional manufacturing industry, the knowledge of labor is generally above a certain level. However, professional obedience and execution ability is generally insufficient. Therefore, problems may occur on the stability issue if we try to implement the TPS system.

Thus, for small and medium-sized manufacturing industries around the world (including Taiwan), they must understand how to integrate manufacturing and service plus getting a true understanding of the value and meaning behind it. In addition, they need to integrate these values into a stream; make the process smooth, and these processes include: product $\mathrm{R} \& \mathrm{D}$, sales, service, marketing, and manufacturing.

A Taiwan-based company needs to figure out how to integrate $R \& D$, production, and $\underline{\text { marketing in the three regions across the Taiwan Strait and effectively refine the overall production }}$ 
and marketing systems to make them lean. In contrast, if TPS is to be implemented in the three regions across the Taiwan Strait, the overall difficulty is relatively much higher. This is because the people of mainland China have different ways of education and their basic concepts are also different from that of the people in Taiwan. In contrast, management methods are also different.

Therefore, we must find out the management model that is suitable for the small and mediumsized traditional manufacturing industry in Taiwan. It is not feasible to follow the same procedure. Traditional manufacturing industries with different attributes also have different focuses. Some emphasize $\mathrm{R} \& \mathrm{D}$, some require optimization of the production processes, and some require rapid marketing. For example, a Large Company focuses on R\&D; their technologies must be at least five years ahead of their competitors, while a mobile phone manufacturer, such as HTC requires the rapidity in marketing, the rapidity of product generation alternation, and the competitiveness in its industry. When there are problems with strategy and marketing, it will lead to the decline of the company.

\section{CONCLUSION AND FURTHER RESEARCH}

$\mathrm{Y}$ factory is a traditional family-owned small to medium-sized enterprise. It has a history of about 40 years since its establishment. In the early days, it used the traditional processing machinery to produce gear racks. There was no so-called accuracy at all, but in an era when resources were scarce, it was still usable.

There was no so-called factory management system 40 years ago. The factory was run using a very primitive management style. The factory was managed with a mentor/apprentice model. It was even more unlikely to have the so-called goal setting. It's a miracle to be able to operate till now.

The factory started to contact the international market in 2008 and realized that there were socalled Lean Management, so-called goal setting, and employee performance management. The company began to introduce these two systems to the internal management of the factory. It tried to improve the management system, increase productivity, reduce waste, and require employees to cooperate with each other to set goals and improve performance.

According to the above-described research background and research motivation, the following research conclusions include:

1. Implement the LP mode, and compare the production efficacy before and after the implementation.

2. Implement the LP mode, in the production process compare the reduced wastes (including human resource waste and manufacturing generated waste) before and after the implementation.

Table 1. Comparison before and after implementation

\begin{tabular}{|c|c|c|c|c|c|}
\hline Comparison & Material & Machining & Heat Process & Grinding & Packing \\
\hline Before & $\begin{array}{l}\text { Planned } \\
\text { order } \\
\text { weekly }\end{array}$ & $\begin{array}{l}\text { Scheduling based } \\
\text { on customer's } \\
\text { order date }\end{array}$ & $\begin{array}{l}\text { Single-vendor } \\
\text { Outsourcing }\end{array}$ & $\begin{array}{l}\text { Single-vendor } \\
\text { Outsourcing }\end{array}$ & $\begin{array}{l}\text { Single-sized } \\
\text { carton, cut to fit. }\end{array}$ \\
\hline After & \begin{tabular}{l}
\multicolumn{2}{c}{ Daily } \\
order based \\
on \\
customer's \\
order
\end{tabular} & $\begin{array}{l}\text { Scheduling } \\
\text { based on } \\
\text { customer's order } \\
\text { delivery date }\end{array}$ & $\begin{array}{l}\quad \text { Multi- } \\
\text { vendors } \\
\text { Outsourcing. }\end{array}$ & $\begin{array}{l}\text { Multi- } \\
\text { vendors } \\
\text { Outsourcing. }\end{array}$ & $\begin{array}{l}\text { Order carton } \\
\text { with different } \\
\text { sizes to fit. }\end{array}$ \\
\hline
\end{tabular}


Due to a large number of employees in the Y factory, we observed two unwanted situations: the competition between colleagues and the division of fractions. These situations reduced job performance and caused employees to slander each other. Therefore, the Y factory introduced the concept of OKR, allowing employees to help each other in setting difficult and clear goals and set performance rewards based on the degree of difficulty in achieving these goals. It also gave rewards based on the achievement rate for individuals and groups helping each other.

Through this study and the implementation of the Lean Production mode, the company reduced unnecessary wastes and achieved real-time information updating. Whether it is on process or the machining flow optimization, the company realized some substantive improvements in lowering the cost and continuous elevation on customer satisfaction. Additionally, in the goal-setting among employees, we tried to set difficult and clear goals and help each other work together to achieve the goals required by the company.

\section{REFERENCES}

Womack, J. P., Jones,D. T.(1996), Lean Thinking: Banish Waste and Create Wealth in your Corporation, 2nd ed. Trans Hanching Chung (2015) Economic Trends Publisher, p12.

John Doerr (2018) Measure What Matters: How Google, Bono, and the Gates Foundation Rock the World with OKRs. Penguin Group (USA) Inc. Trans SHIU,RUEI-SUNG (2019), Commonwealth Publisher, p16-21. 